\title{
Optimization Analysis of Rural Cooperative Economic Organization
}

\author{
Li Liu \\ Marxism College of Jilin agricultural University Jilin Changchun, 130118, China
}

\begin{abstract}
In 1980s, the farmer specialized cooperative economic organization in our country rises and develops rapidly. For farmers, the new rural cooperative economic organization is conducive to improve the negotiation ability of the farmers, improve the economic status of farmers, and increase the income of farmers. Overall, under the background of the market economy, agricultural industrialization, and economic globalization, China's new rural cooperative economic organization has very good effect on solving the "small farmers" and "big market" contradictions. The role that China's rural cooperative economic organizations plays is given great expectations, but because China's The new rural cooperative economic organization is still in the initial stage of development, in many ways, it shows the imperfections. There are some evident problems existing in the new rural cooperative economic organization of our country. They are fuzzy property boundaries, unreasonable decision-making mechanism, the inefficient operating mechanism, ineffective oversight mechanisms, incentive mechanism, and irrational allocation mechanism of new rural cooperative economic organization. In addition, the legal status is not clear, government support is insufficient, external financing is in shortage and so on. The defects of China's new rural cooperative economic organization have hindered its role to a great extent. In consequence, if we can solve or alleviate the problems of the new rural cooperative economic organization, it will beyond doubt create a greater development space for our new rural cooperative economic organization.
\end{abstract}

Keywords: Rural cooperative economic organization; Optimization; Measurements.

\section{Introduction}

China is a large agricultural country, and agriculture is the foundation of our national economy and it has a pivotal position. In consequence, the rural and agricultural development and the improvement of the living standards of farmers have been concerned for many years. In the period that Kuomintang holds power, the government has taken some measures to promote the development of cooperatives, such as the Legislative established Chinese Cooperative Law. But under the historical conditions at that time, the changing situation made that cooperative coverage was still very small, so its role is not obvious. Figure 1 shows the development of rural cooperatives in February in 1928 1949 [1]. It can be seen that in this 20 years, the number of the rural cooperatives was growing and it was more than 180 times.

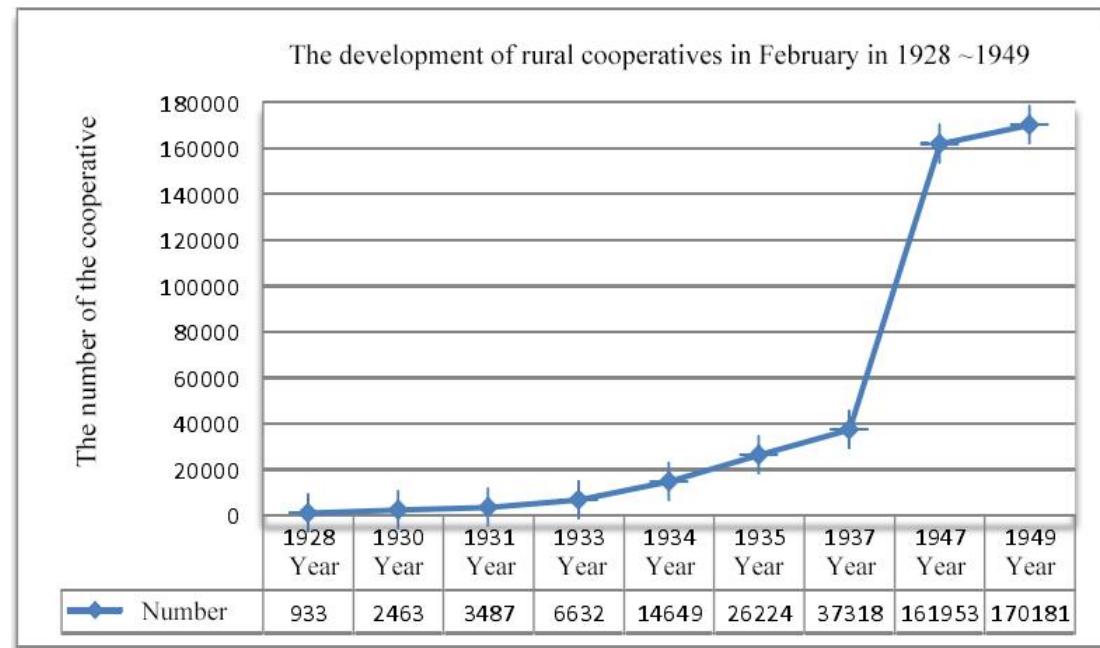

Figure 1 The development of rural cooperatives in February in $1928 \sim 1949$ 
Although there are many rural cooperative economic organizations existing in China, we must clearly recognize that, compared with the earlier developed countries and regions, rural cooperative economic organization in China is still in the initial stage of development, and their development is not perfect. It has the problems that the structure of property rights is not clear, the internal governance structure is not scientific and so on. In terms of decision-making mechanism, management mechanism, supervision mechanism, incentive mechanism, and distribution mechanism, it is necessary to be optimized. As a result, take effective measures to optimize the rural cooperative economic organization in China is of great importance. It can not only make the new rural cooperative economic organization between farmer and market better play the role so that the majority of farmers get more economic benefits, but also can promote the smooth development of China's agricultural modernization, make agriculture better play the basic role of the national economy, so China's agriculture become more competitive in the international market.

\section{A Brief Introduction to Rural Cooperative Economic Organization}

The rural cooperative economic organization refers to "in the restriction of the external environment (policy, economic, legal, technical and social capital) and their own conditions, based on the common interest of production and business operation, special economic pert set up by individuals and organizations engaged in agricultural production, processing and circulation through a certain cooperative mechanism on the basis of voluntary and mutually beneficial".

The types of rural cooperative economic organization in China, from different angles, have different divisions. In accordance with the close degree of cooperation, the rural cooperative economic organization (that is, the farmer specialized cooperative economic organization) is divided into professional cooperatives, Joint stock cooperative, and professional associations, as shown in Figure 2 [2]. The professional cooperative in the legal status is the enterprise legal person. The members of the professional cooperatives have formed a relatively close relationship with the economic interests.

The leading of joint shares cooperative is generally agricultural extension departments or enterprises etc. Shares of cooperatives in the law has also been characterized as an enterprise legal person, and most have their own business. The main feature of this type of rural cooperative economic organization is the combination of "joint stock system" and "cooperative system", and the combination of "labor union" and "capital union". Overall, the proportion of the share of cooperatives in the rural cooperative economic organization is less than professional cooperatives. Professional associations include two types of associations and research institutions. Its feature is relatively loose. They are mostly registered in the Civil Affairs Department as community organization, and now it should be the main form of rural cooperative economic organization.

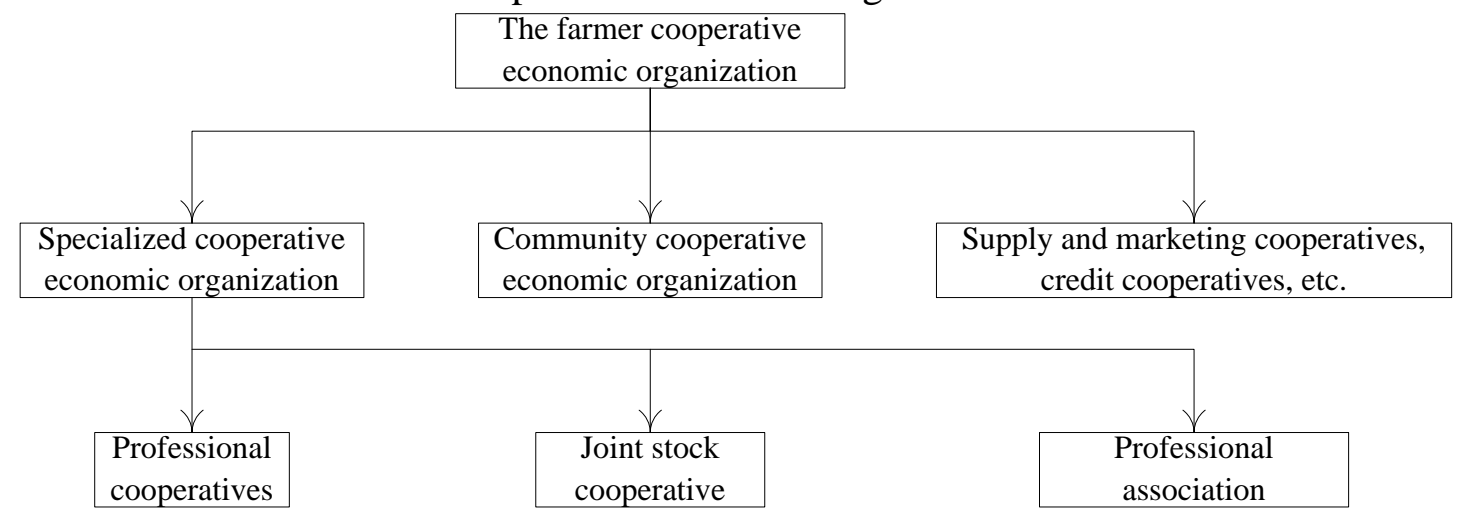

Figure 2 Classification of rural cooperative economic organization 


\section{Problems Existing in Rural Cooperative Economic Organization}

\subsection{Unclear Property Rights}

At the beginning of the establishment of China's rural cooperative economic organization, limited by scale, capital, capacity and other factors, it mainly relies on government departments, rural collective organizations, large plantations, large farms and so on (call them "Depending on the entity") to set up, and at the beginning of the establishment, the property rights are not clear [3]. With the continuous development of the organization, the scale is expanding, the profitability of the organization itself and the country's various support funds have increased to a certain degree. In this way, "Depending on the entity" has controversy with organization in the new asset ownership, the distribution of surplus, and the division of responsibilities, especially in the common property accumulation that has the common property rights, because the public accumulation is the property that actually has no real owners.

But with the continuous expansion of the scale of the rural cooperative economic organization and the value of the assets continues to rise, the absence of public accumulation of property relations and fuzzy property rights, the rural cooperative economic organizations will be affected. In addition, the unclear property right will have adverse effects on other aspects of new rural cooperative economic organizations, such as "Depending on the entity" has great difference with the ordinary members in the capital ratio. In addition, the unclear boundary of property rights also makes some resources (including tangible resources and intangible resources) of the new type of rural cooperative economic organization is excessive used or inadequately used. It also gives great living space for opportunism. Because when there is a problem, not only the new rural cooperative economic organizations cannot be separated from the division of responsibility of the entity, but the division of responsibilities within the new rural cooperative economic organizations are difficult to distinguish boundaries, which makes the opportunism get chances.

\subsection{Insufficient Government Support}

A lot of new rural cooperative economic organizations in China rely on government departments to establish, and at the beginning of the establishment, it gets the government's support. This also makes that the government plays an essential role in the new rural cooperative economic organization from the beginning. There is no doubt that the government departments indeed have great influence on the development of new rural cooperative economic organization, but in reality there is also the phenomenon that the positioning of government in the new rural cooperative economic organization is incorrect. For example, the leader of the rural cooperative economic organization is occupied by the government officers, or the government chooses a person who can consider their interests to serve it [4]. In addition, the government has too much involvement in the management and decision-making of new rural cooperative economic organizations, rather than as a guide to regulate and support its development. This makes the decision-making power and supervision rights of the majority of the members cannot be implemented. The development of the rural cooperative economic organizations is trapped in the planned economy pattern to a certain extent.

Moreover, the support of government in many areas for the new rural cooperative economic organization is not enough that government departments did not provide sufficient institutional supply or adequate infrastructure or services for the development of rural cooperative economic organization etc. It should be emphasized that China's rural cooperative economic organization is in the initial stage of development, the rural cooperative economic organizations in this period especially needs the government to create a good system environment.

\subsection{Lack of Financing Channels}

No matter what type the organization is, money is like the blood of its operation, and it is the material basis for its development. But at present, the rural cooperative economic organization in our country is in a state of general lack of funds. The factors for this situation are of variety. One is that China's new rural cooperative economic organization internal financing is very limited, and the second is too few external financing channels. Because from the reality of our country, the nature of the rural cooperative economic organization determines that it cannot finance from the public as the 
joint-stock company does, their external financing channel is in fact mainly financial support from the government, loans from financial institutions etc. But at the moment, we are not doing enough in this respect. Specifically speaking, the loan ratio for China's commercial banks for farmers and agricultural organizations and business is very low. It is reported that the loan that the Agricultural Bank invested in rural areas accounted for only $10 \%$ of the amount of total loans [5]. Although over the past 50 years, the rural credit cooperatives have become a part of the financial system of our country, and it plays an important role in meeting the needs of the farmers. But we should not forget that the essence of rural credit cooperative is a form of rural cooperative economic organization, and its own also has many problems, so the supporting force of it on the new rural cooperative economic organizations is very limited. Therefore, at present, farmers rely mainly on private credit to ease the shortage of funds. In short, the funds have always been the bottleneck of the development of new rural cooperative economic organizations in China.

\section{Measurements to Optimize the Rural Cooperative Economic Organization}

\subsection{Clarify the Relationship of Property Rights}

With the increase of the membership heterogeneity of the rural cooperative economic organization of our country and the improvement of the economic value of new rural cooperative economic organization, the constraints faced by new rural cooperative economic organization have also changed. Therefore, to further clarify the property becomes profitable. So, how to make the rural cooperative economic organization's property rights relationship more clearly?

First of all, at the beginning of the establishment of the rural cooperative economic organization, clarify the relationship of property rights between "Depending on the entity" and the rural cooperative economic organization, so as to avoid, with the development of rural cooperative economic organization, the incremental assets between the two cannot be accurately defined. In the equity ownership, it is supposed to adopt a balanced share principle, so as to avoid the change of properties of new rural cooperative economic organization.

Secondly, the rural cooperative economic organizations should clarify the property rights of the members within the organization, set up personal account for the members in accordance with the law and the articles, and the rural cooperative economic organization is supposed to make a clear division of assets with different natures and functions. Additionally, to do a good job in the division of public accumulation [6]. Specific approach may be: first of all, the new rural cooperative economic organization's surplus is returned to the members according to the amount of the transaction, and then extract a part of it as the public accumulation, and the accumulation is included in the individual accounts of the members. At this time, the proportion of extraction and accumulation should be controlled in a certain ratio or quantity. For the rest of the assets, based on the length of time that the members participate in the association and the amount of the transaction, the shares of member appreciation is improved in the book. Except for the above three measures, it is also necessary to establish equity transferring System, allowing the transfer of ownership within the organization, and allow the appropriate absorption of foreign funds.

\subsection{Government to Create a Good System Environment}

Government intervention in China's rural cooperative economic organization cannot be too deep nor neglect it. That is to say, the government should handle the relationship between it and the new rural cooperative economic organization with "supporters" and "supervisor" identity. In the propaganda, it is necessary to take active and effective measurements, so farmers have a more accurate understanding of the rural cooperative economic organization and its effect; in the system, the government needs to develop relevant laws and regulations to regulate the rural cooperative economic organization; in the supervision, it is supposed to proceed real and effective external supervision on the type of rural cooperative economic organization; at the same time, it is rather essential to provide timely and accurate information for agriculture in the rural cooperative economic organization. In addition, the government should actively and steadily accelerate the construction of a 
variety of infrastructure in rural areas, so as to make agricultural production and sales of the new rural cooperative organization more convenient, more time-saving, and more efficient.

\subsection{The External to Provide Financial Support and Make Foreign Investment}

On the one hand, it needs the financial and tax support. In terms of finance, financial departments at all levels can prepare a special fund for the rural cooperative economic organization to support for the development of new rural cooperative economic organization, or provides financial subsidies to it. In addition, provide subsides for the upstream suppliers of the rural cooperative economic organization. For example, carry out appropriate subsidies for the suppliers where the rural cooperative economic organization purchased some of the production equipment. Second, financial support [7]. First of all, to play the role of policy banks. Agricultural Development Bank as a national policy bank, the new type of rural cooperative economic organizations can be more preferential support.

On the other hand, the financial support is necessary. First of all, fully make use of the role that policy-oriented bank plays. Agricultural Develop Bank, as the policy-oriented bank of our country, can carry out more preferential support for the rural cooperative economic organization. Secondly, it requires to play the role of commercial banks and rural cooperative financial organizations. Encourage commercial banks to provide more preferential loans for rural cooperative economic organization. For commercial banks having business with the rural cooperative economic organization, the state can provide some preferential policies to support the rural cooperative economic organization. Thirdly, they themselves carry out foreign investment. In order to solve the shortage of funds of the rural cooperative economic organization, the rural cooperative economic organizations in China can also learn from corporate practices, to properly issue investment shares, or appropriately invest in the capital market.

\section{Conclusion}

Under the era background of market economy, agricultural industrialization, and economic globalization, China's rural cooperative economic organization has a good effect on solving the contradiction between "small farmers" and "big market". But because of our country's rural cooperative economic organization is still in the initial stage of development, there are still a lot of problems remaining to be solved. This paper mainly discusses three problems of unclear property rights, insufficient government support, and lack of external financing channels. By further analyzing, this paper puts forward some measurements for optimizing the rural cooperative economic organization [8]. They are clarifying the relationship between property rights, government to create a good system environment and enhance their supporting forces for the rural cooperative economic organization, and the last one the external to provide financial support and the organization itself makes some foreign investment. Only with the joint effort of these three aspects, can the rural cooperative economic organization get a better development so as to be perfect gradually.

\section{References}

[1] Hairong Y, Yiyuan C. Debating the rural cooperative movement in China, the past and the present [J]. Journal of Peasant Studies, 2013, 40(6): 955-981.

[2] Nembhard J G. Collective courage: A history of African American cooperative economic thought and practice [M]. Penn State Press, 2014.

[3] Boone C, Özcan S. Why do cooperatives emerge in a world dominated by corporations? The diffusion of cooperatives in the US bio-ethanol industry, 1978-2013[J]. Academy of Management Journal, 2014, 57(4): 990-1012. 
[4] Pan B, Yuan Z, Zou J, et al. Elderly hospitalization and the New-type Rural Cooperative Medical Scheme (NCMS) in China: multi-stage cross-sectional surveys of Jiangxi province [J]. BMC Health Services Research, 2016, 16(1): 436.

[5] Li C, Hou Y, Sun M, et al. An evaluation of China's new rural cooperative medical system: achievements and inadequacies from policy goals[J]. BMC public health, 2015, 15(1): 1.

[6] Meng Q, Xu K. Progress and challenges of the rural cooperative medical scheme in China [J]. Bulletin of the World Health Organization, 2014, 92(6): 447-451.

[7] You H, Gu H, Ning W, et al. Comparing Maternal Services Utilization and Expense Reimbursement before and after the Adjustment of the New Rural Cooperative Medical Scheme Policy in Rural China[J]. PloS one, 2016, 11(7): e0158473.

[8] Sun M, Shen J J, Li C, et al. Effects of China's New Rural Cooperative Medical Scheme on reducing medical impoverishment in rural Yanbian: An alternative approach [J]. BMC Health Services Research, 2016, 16(1): 422. 